\title{
Increased expressions of cellular ATP-binding cassette transporters may be a promising diagnostic marker for colorectal cancer
}

Renad M. Qutub, BSc, MSc, Ayat B. Al-Ghafari, MSc, PhD, Huda A. Al Doghaither, MSc, PhD, Ulfat M. Omar, MSc, PhD, Jihan M. Ghulam, BSc.

\begin{abstract}

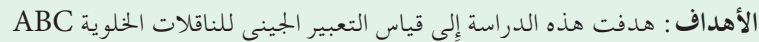

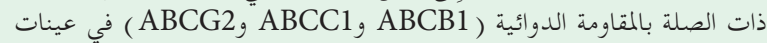

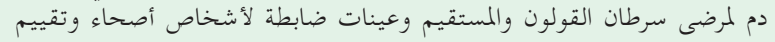

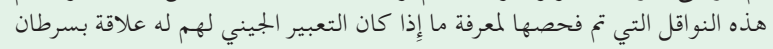

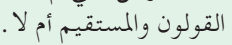

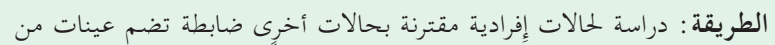

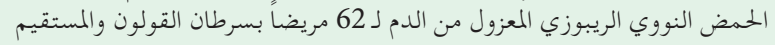

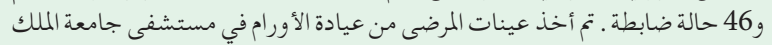

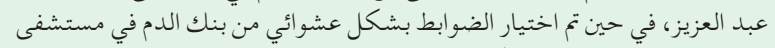

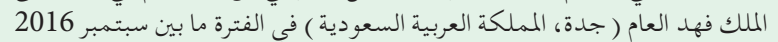

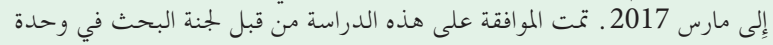

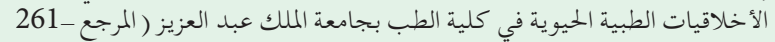

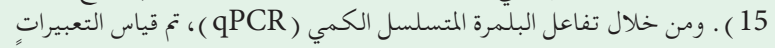

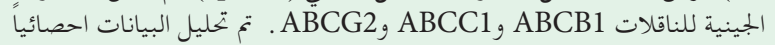

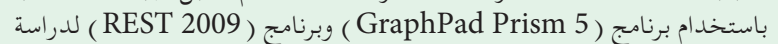

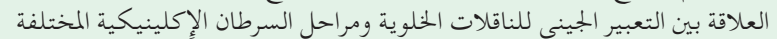

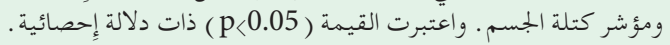

النتائج : أظهرت نتائج هذه الدراسة أن ناقلات ABC الثلاثة تح التعبير عنها

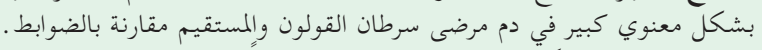

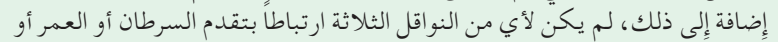

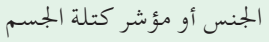

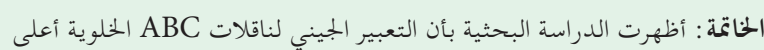

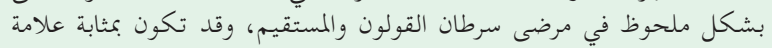

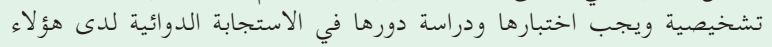

Objectives: To measure the blood expression levels of related drug-resistant ATP-binding cassette (ABC) transporters in colorectal cancer (CRC) patients and to assess these examined transporters for whether they present significant expression in connection with the tumor appearance of CRC.

Methods: In this case-control study, the messenger ribonucleic acids were isolated from the blood of 62 CRC patients who were recruited from King Abdulaziz University Hospital Oncology Clinic and 46 controls from King Fahad General Hospital Blood Bank (Jeddah, Saudi Arabia) from September 2016 to March 2017. The Biomedical Ethics Unit at King Abdulaziz University, Jeddah, Saudi Arabia approved this study. The expressions of $\mathrm{ABC}$ transporters were measured using quantitative polymerase chain reaction. GraphPad Prism 5 and REST 2009 Software were used to correlate the expressions with clinicopathological independent stages and body mass index. A $p$-value of less than 0.05 was considered significant.

Results: The results showed that the $3 \mathrm{ABC}$ transporters, particularly ABCC1 $(p<0.0001)$, were highly expressed in the blood of CRC patients compared with controls. However, none of the 3 transporters was related to the progression of CRC, age, gender, or body mass index.

Conclusion: The expressions of $\mathrm{ABC}$ transporters were found to be significantly higher in CRC patients, and they may act as diagnostic markers and should potentially be tested for their contribution to drug sensitivity in CRC patients.

Keywords: ABCB1, ABCC1, ABCG2, colorectal cancer, diagnosis

Saudi Med J 2020; Vol. 41 (8): 834-840 doi: $10.15537 /$ smj.2020.8.25187

From the Biochemistry Department (Qutub, Al-Ghafari, AlDoghaither, Omar), Faculty of Science; from the Experimental Biochemistry Unit (Al-Ghafari), King Fahad Medical Research Centre, King Abdulaziz University; and from the General Education Department (Ghulam), Dar Al-Hekma University, Jeddah, Kingdom of Saudi Arabia.

Received 26th April 2020. Accepted 24th June 2020.

Address correspondence and reprint request to: Dr. Ayat B. Al-Ghafari, BiochemistryDepartment, Faculty ofScience, KingAbdulazizUniversity, Jeddah, Kingdom of Saudi Arabia. E-mail: abalghafari@kau.edu.sa ORCID ID: https://orcid.org/0000-0001-9156-4263 
C olorectal cancer (CRC) is a type of cancer that has been classified as a prime reason for cancerrelated death around the world. ${ }^{1}$ Since 2002, CRC has been recorded as the most common cancer in Saudi Arabia. ${ }^{2}$ There are many reasons for this enhanced incidence, such as the age of the population, increase in unhealthy dietary habits, low physical activity, obesity, and smoking. ${ }^{3-5}$ Moreover, there are some genetic and environmental factors that boost carcinogenesis in the colon epithelial cells by supporting the cumulative gathering of epigenetic and genetic alterations that turn on the oncogenes and turn off the tumor suppressor genes. ${ }^{6}$ These features can be a sign for diagnosing CRC. Such a diagnosis could either stem from a patient's exhibiting symptoms or be an outcome of an examination. ${ }^{7}$

During treatment, the effectiveness of therapy may decrease, which can lead to a reduction in the pharmacokinetics, pharmacodynamics, and pharmacogenomics of the drug; this is clinically known as drug resistance. ${ }^{8,9}$ Cellular mechanisms of multidrug resistance (MDR) refer to the decrease in anticancer drugs' intracellular collection due to the passage of the drugs out of cancer cells via various membrane transporters. ${ }^{8,9}$ Four types of membrane transporters are involved in MDR; among them is the ATP-powered pumps (ATP-binding cassette $[\mathrm{ABC}]$ transporters). ${ }^{10,11}$

ATP-binding cassette transporters are implicated in the cellular prefix of many molecule groups, such as lipids, cholesterol, sterols, bile acid, retinoic acid derivatives, iron, peptides, and nucleosides. There are $49 \mathrm{ABC}$ transporter members, which can be phylogenetically divided into 7 classes (A-G). ${ }^{12,13}$ Three types of ABC transporters (ABCB1, $\mathrm{ABCC} 1$, and $\mathrm{ABCG} 2$ ) are involved in drug resistance against antimicrobial and anticancer drugs. In cancer cells, several members of the B subfamily, particularly ABCB1, are known to confer multidrug resistance (MDR). ${ }^{14}$ The ABCC subfamily encodes many transporters that are linked with MDR. There are various actions of the ABCC transporters involved, namely, ion channels, the activity of toxin excretion, and reception on the cell surface. ${ }^{15}$ The ABCG subfamily contains several half transporters that are involved in atherosclerosis and sterol accumulation disorders. In MDR, ABCG2 works on transporting certain chlorophyll metabolites and steroids (estradiol,

Disclosure. Authors have no conflict of interests, and the work was not supported or funded by any drug company. cholesterol, progesterone, and testosterone), as well as organic anions. ${ }^{14}$

In treatment, $A B C$ transporters seem to play a role in completing the therapy or achieving recovery. 5-fluorouracil (5-FU)-based chemotherapy still leads as one of the main types of therapy for CRC patients since the 1950s. Irinotecan, oxaliplatin, and capecitabine are chemotherapy drugs that have recently been developed. ${ }^{16-19}$ Combining leucovorin and 5-FU with irinotecan or oxaliplatin is the traditional treatment for precedent CRC encompasses. In CRC, cetuximab and bevacizumab are medical treatments that represent a huge advancement in the development of monoclonal antibodies. Regardless of the progression in the rates of response with various modified treatment strategies, the 5-year survival rate for metastatic CRC (mCRC) patients is only slightly above $12 \%$ due to overexpression of $\mathrm{ABC}$ transporters. ${ }^{20}$ As far as we are aware, there are no reports in Saudi Arabia that have measured the messenger ribonucleic acids (mRNA) expression of major drug-resistant $\mathrm{ABC}$ transporters, $\mathrm{ABCB} 1, \mathrm{ABCC} 1$, and $\mathrm{ABCG} 2$, in the blood of CRC patients. Therefore, the aim of the study is to identify the expression of these transporters to delineate their contribution to CRC prognosis and diagnosis.

Methods. Chemical reagents and kits. The QIAamp RNA blood mini kit (catalog no: 52304) was purchased from QIAGEN (Germany). The high capacity complementary deoxyribonucleic acid (cDNA) reverse transcription kit (catalog no: 4368814) was purchased from Thermo Fisher Scientific (Vilnius, Lithuania). RNase inhibitor (catalog no. N8080119) was purchased from Thermo Fisher Scientific, (USA). Universal 2xPowerUP ${ }^{\mathrm{TM}} \mathrm{SYBR}^{\odot}$ Green Master Mix Kit (catalog no: A25741) was ordered from (Thermo Fisher Scientific, USA).

Subject and samples. In this case-control study, 2-ml whole blood EDTA vacutainer tubes were collected from 108 Saudi participants (62 CRC patients and 46 controls, aged 30 to 80 years) in the study period (September 2016 to March 2017) in Jeddah, Western Region of Saudi Arabia. Colorectal cancer patients were recruited from King Abdulaziz University Hospital, Jeddah, Saudi Arabia (oncology clinics), whereas the controls were selected randomly from King Fahad General Hospital (blood bank). The inclusion criteria for CRC participants were Saudi patients recently diagnosed with colon carcinoma or adenocarcinoma. Those patients were selected based on their biopsies or colonoscopy medical reports confirming the diagnosis comprising an updated personal and clinical history, treatment regimen, and tumor pathology data. 
On the other hand, the exclusion criteria were non-Saudi patients or those having colon cancer as a secondary tumor. The controls were selected if they met the following criteria: had no current metabolic or previous cancer incidence and showed general good health status based on their clinical examination and laboratory investigations. Any control with previous family history of CRC was excluded from the study.

This study followed the principles of the Declarations of Helsinki in dealing with patients' information, samples, and results. All participants read and signed a consent form. The practical work was performed at the King Fahad Medical Research Center (Cancer Mutagenesis Unit), King Abdulaziz University, Jeddah, Saudi Arabia. The research committee of the Biomedical Ethics Unit at Faculty of Medicine, King Abdulaziz University approved this study (under reference number 261-15).

Extraction and purification of $m R N A$ samples. Intact RNA samples $(\mathrm{ng} / \mu \mathrm{l})$ were extracted from blood using a QIAamp RNA blood mini kit. The concentrations of extracted RNA samples were immediately determined with a Nanodrop spectrophotometer $\left(\lambda_{260} \mathrm{~nm}\right)$. The A260 readings were carried out at greater than 0.15 to ensure the significance of intact and purified RNA samples, and the readings' ratio (A260/A280) ranged from 1.9 to 2.1. Any samples that failed to fulfill these reading parameters were immediately replaced with other samples. All extracted RNA samples were kept at $-80^{\circ} \mathrm{C}$ until analysis.

Synthesis of complementary DNA (cDNA). The cDNAs $(20 \mu \mathrm{l})$ were reverse transcribed from highly purified extracted RNA samples $(300 \mathrm{ng} / \mu \mathrm{l})$ using the random primer scheme of a high capacity cDNA Reverse Transcription kit. Then, to prevent the degradation of RNA during the reverse transcription process, RNase inhibitor was added to the cDNA synthesis reagents.

Quantitative polymerase chain reaction ( $q P C R$ ) primer design and preparation. Specifically designed primers for $\mathrm{qPCR}$ were used to measure the expression of $\mathrm{ABC}$ transporters alongside the housekeeping gene glyceraldehyde-3-phosphate (GAPDH). By using the USCS genome online services, primer sequences of the 3 ABC transporters were obtained. After confirming all the primer characteristics, the exons of mRNA (Homo sapiens) were taken and then the specific primer pairs were designed using the Primer 3 Software. A further verification was performed for the designed primers using the USCS browser (in silico PCR). Then, nucleasefree water was added to each freeze-dried powder primer to form a final $100 \mu \mathrm{M}$ stock primer.

Quantitative polymerase chain reaction. The expression levels of $\mathrm{ABC}$ transporters were determined by qPCR using the SYBR Green protocol. To prepare the reaction $(20 \mu \mathrm{l} / \mathrm{well}), 1 \mu \mathrm{l}$ of corresponding cDNA was mixed with the appropriate amount of Universal 2xPowerUP ${ }^{\mathrm{TM}} \mathrm{SYBR}^{\oplus}$ Green Master Mix Kit, nuclease free water, and $10 \mu \mathrm{M}$ of each forward and reverse primer of $A B C$ transporter $[A B C B 1$ forward primer 5'-TCCTCTCATGATGCTGGTGT-3' and reverse primer 5'-TGGTCATGTCTTCCTCCAGA-3'; ABCC1 forward primer 5'-GTGGACCTGTTTCGTGACAT-3' and reverse primer 5'- GGATTAGGGTCGTGGATGGT-3'; and ABCG2 forward primer 5'-TGCTGTCCTTTTGCTCCTGA-3' and reverse primer 5'-CAAAGTATCCCAAGGCCTCC-3'] or housekeeping gene (GAPDH) [forward primer 5'-CACATCGCTCAGACACCATG-3' and reverse primer 5'-ACCAGAGTTAAAAGCAGCCC-3']. Then, the following settings of the thermal cycler conditions [Uracil-DNA glycosylase activation step at $50^{\circ} \mathrm{C}$ for 2 minutes, DNA polymerase Dual-Lock ${ }^{\mathrm{TM}}$ step at $95^{\circ} \mathrm{C}$ for 2 minutes, denaturation step at $95^{\circ} \mathrm{C}$ for 15 seconds (40 cycles), annealing step at $60^{\circ} \mathrm{C}$ for 1 minute $(40$ cycles), and extension step at $60^{\circ} \mathrm{C}$ for 1 minute $(40$ cycles)] were applied. To ensure the reproducibility of the expression results, for each $\mathrm{ABC}$ transporter, a duplicate run was performed for each sample, and the mean was calculated.

Statistical analysis. All statistical analyses were performed using GraphPad Prism Version 5.0 (GraphPad Software Inc., San Diego, CA, USA). Descriptive data were expressed as mean \pm standard error of the mean (SEM). The physical parameter comparisons were calculated by Mann-Whitney test. In contrast, the analysis of qPCR raw data was performed in 2 steps. First, the expression data for $\mathrm{ABC}$ transporters were normalized to the expression of GAPDH housekeeping gene using the REST 2009 software program. Then, the normalized results were compared using an unpaired t-test with Welch's correction to calculate the degree of differences between 2 independent groups. Moreover, a one-way ANOVA test was used to determine the presence of any statistically significant differences between the means of $\mathrm{ABC}$ transporter expression in the 4 clinicopathological independent stages and body mass index (BMI). The mean and $p$-values of the one-way ANOVA test were corrected with Bartlett's test to verify that the variances were equal across groups or samples (population under normal distribution assumption). A $p$-value of less than 0.05 was considered statistically significant.

Results. Expression of $A B C$ transporters in the blood of CRC patients and controls. With the 
application of the Mann-Whitney test (Table 1), the analysis showed that there were significant differences between CRC patients and controls regarding the 3 following physical parameters: body weight, BMI, and waist-to-hip ratio. These physical parameters were higher in healthy controls compared with CRC patients. Other physical parameters, such as age, height, waist circumference, and hip circumference did not show significant differences.

Regarding the mRNA expression levels of ABCB1, $A B C C 1$, and $A B C G 2$ transporters in the blood of CRC patients (Figure 1), the results revealed significant differences in the expression levels of the $3 \mathrm{ABC}$ transporters in patients compared to the healthy controls (Table 2).

Relationship between the expressions of $A B C$ transporters and CRC progression. Relying on Duke's classification, the patients in this study were classified into 4 different groups, which were as follows: stage I $(n=7,11.3 \%)$, stage II $(n=7,11.3 \%)$, stage III $(\mathrm{n}=17,27.4 \%)$, and stage IV $(\mathrm{n}=31,50 \%)$. In this study, there were no patients determined to be at stage 0 . When the expression means of each $\mathrm{ABC}$ transporter were compared in different stages via a one-way

Table 1 - Demographic characteristics of study subjects ( $N=108)$.

\begin{tabular}{lccc}
\hline Characteristic (unit) & $\begin{array}{c}\text { CRC patients } \\
(\mathbf{n}=62) \\
\text { Mean } \pm \text { SEM }\end{array}$ & $\begin{array}{c}\text { Controls } \\
(\mathbf{n}=46) \\
\text { Mean } \pm \text { SEM }\end{array}$ & $P$-value \\
\hline Body weight $(\mathrm{kg})$ & $73.76 \pm 2.01$ & $83.78 \pm 2.58$ & 0.005 \\
$\begin{array}{l}\text { Body mass index } \\
\left(\mathrm{kg} / \mathrm{m}^{2}\right)\end{array}$ & $27.08 \pm 0.73$ & $31.04 \pm 0.98$ & 0.004 \\
Waist-to-hip ratio & $0.92 \pm 0.02$ & $0.99 \pm 0.02$ & 0.02 \\
Age (years) & $56.52 \pm 1.54$ & $52.13 \pm 1.83$ & 0.07 \\
Height $(\mathrm{cm})$ & $165.1 \pm 1.18$ & $164.5 \pm 1.17$ & 0.82 \\
$\begin{array}{l}\text { Waist circumference } \\
(\mathrm{cm})\end{array}$ & $101.1 \pm 2.54$ & $104 \pm 2.83$ & 0.96 \\
Hip circumference $(\mathrm{cm})$ & $110.5 \pm 2.39$ & $106.5 \pm 2.80$ & 0.13 \\
\hline \multicolumn{4}{c}{ SEM: standard error of the mean, CRC: colorectal cancer } \\
\hline \multicolumn{4}{c}{} \\
\hline
\end{tabular}

ANOVA test to reveal their contribution to progression, the results showed non-significant differences for the 3 ABC transporters (Table 3). The results of the expression levels for each stage indicated that there was no considerable influence of these transporters on the progression of CRC, although their expression was higher compared to the control group.

Relationship between the expressions of $A B C$ transporters and gender, age, and BMI in CRC patients. To study the effect of $\mathrm{ABC}$ transporters on physical attributes rather than clinical ones, CRC patients $(n=62)$ were divided according to their gender into females $(n=15,24.2 \%)$ and males $(n=47,75.8 \%)$. The comparison established by the unpaired t-test showed that none of the $\mathrm{ABC}$ transporters had a significant relationship with gender (Table 4). The expressions of $\mathrm{ABC}$ transporters in male patients compared to female

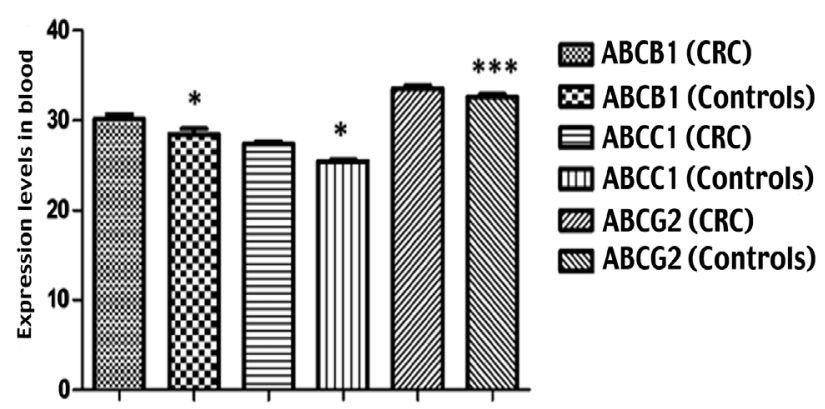

Figure 1 - Expression levels of mRNA for $A B C$ transporters. The expression levels of each $A B C$ transporter were determined using $\mathrm{qPCR}$ technique. Their expressions were normalized to the expression of GAPDH housekeeping gene using REST 2009 software. Then, the normalized results were compared using an unpaired t-test with Welch's correction to calculate the degree of differences in expression between two independent groups. Regarding the mRNA expression levels of $\mathrm{ABCB} 1, \mathrm{ABCC} 1$, and $\mathrm{ABCG} 2$ transporters in the blood of CRC patients, the results showed a significant difference in the expression levels of the three $\mathrm{ABC}$ transporters (these were higher in CRC patients compared with healthy controls). P values were as follows: ${ }^{*} p<0.05 ;{ }^{* * *} p<0.0001$.

Table 2 - Blood expression levels of ATP-binding cassette (ABC) transporters in colorectal cancer (CRC) patients and controls.

\begin{tabular}{lccccc}
\hline Transporters & $\begin{array}{c}\text { CRC patients } \\
(\mathbf{n}=62) \\
\text { Mean } \pm \text { SEM }\end{array}$ & $\begin{array}{c}\text { Controls } \\
(\mathbf{n}=46) \\
\text { Mean } \pm \text { SEM }\end{array}$ & $\begin{array}{c}\text { Corrected } \\
\text { unpaired t-test } \\
P \text {-value }\end{array}$ & $\begin{array}{c}\text { Difference between means } \\
(\mathbf{9 5 \%} \text { CI })\end{array}$ & $\mathbf{R}^{2}$ \\
\hline ABCB1 & $30.18 \pm 0.49$ & $28.50 \pm 0.59$ & $0.03^{*}$ & $\begin{array}{c}1.69 \pm 0.77 \\
(0.16-3.22)\end{array}$ & 0.05 \\
ABCC1 & $27.38 \pm 0.29$ & $25.45 \pm 0.19$ & $<0.0001^{\dagger}$ & $\begin{array}{r}1.94 \pm 0.34 \\
(1.25-2.62)\end{array}$ & 0.24 \\
& & & $0.96 \pm 0.47$ & 0.04 \\
ABCG2 & $33.57 \pm 0.34$ & $32.61 \pm 0.32$ & $0.04^{*}$ & $0.04-1.89)$ & \\
\hline
\end{tabular}

${ }^{*} p<0.05,{ }^{\dagger} p<0.0001$ 
patients were as follows: ABCB1, $29.53 \pm 0.86$ vs. 28.21 $\pm 2.17, p=0.50 ; \mathrm{ABCC} 1,27.58 \pm 0.37$ vs. $26.76 \pm 0.23$, $p=0.22$; and ABCG2, $31.18 \pm 0.90$ vs. $28.91 \pm 2.31$, $p=0.27$.

The age of the CRC patients was also divided into 2 groups according to the mean age of 56 years, with one group of CRC patients under $56(n=37,59.7 \%)$ and one above $56(n=25,40.3 \%)$. The expression levels among CRC patients $\geq 56$ years and CRC patients $<56$ years were $27.26 \pm 1.81$ and $30.53 \pm 0.59, p=0.05$, for $\mathrm{ABCB} 1 ; 26.81 \pm 0.16$ and $27.77 \pm 0.46, p=0.09$, for $\mathrm{ABCC} 1$; and $31.66 \pm 0.73$ and $29.93 \pm 1.39, p=0.34$, for ABCG2. The results showed no significant difference between the expressions of $\mathrm{ABC}$ transporters in CRC patients with the onset of age (Table 4).

As BMI showed a significant reduction in CRC patients compared with healthy controls, this study determined the relationship between $\mathrm{ABC}$ transporters and BMI. Colorectal cancer patients were classified according their BMIs into the 4 following groups: group 1 was underweight, with BMIs $<18.5 \mathrm{~kg} / \mathrm{m}^{2}$; group 2 had normal weight, with BMIs ranging from 18.5 to $24.9 \mathrm{~kg} / \mathrm{m}^{2}$; group 3 was overweight, with BMIs ranging from 25 to $29.9 \mathrm{~kg} / \mathrm{m}^{2}$; and group 4 was obese, with BMIs $\geq 30 \mathrm{~kg} / \mathrm{m}^{2}$. The expression level of each $\mathrm{ABC}$ transporter was compared between the 4 categories, and the results are listed in Table 5. However, none of the transporters showed significant differences between the 4 BMI categories.

Discussion. Colorectal cancer is a type of cancer that is widespread in the world as well as in Saudi Arabia. It has been reported as the most common cancer in Saudi Arabia since 2002. ${ }^{2,21}$ The highest incidence of CRC mortality is due to poor response to drugs. One of the best studied mechanisms that allows drug resistance in cancer cells is the over expression of $\mathrm{ABC}$ transporters on the plasma membrane. ATP-binding cassette transporters play an important role in the distribution of diseases, including tumors. ${ }^{22-25}$ Despite intensive treatment and a better understanding of the principles of molecular biology, CRC has a high degree of recurrence and drug resistance $(90 \%$ of patients with metastatic cancer suffer from treatment failure due to drug resistance). ${ }^{9,26,27}$ Relying on these studies, which showed the significant connection between $\mathrm{ABC}$ transporters and cancer, the aim of the present study was to determine the expression levels of $\mathrm{ABC}$ transporters, namely $\mathrm{ABCB} 1, \mathrm{ABCC} 1$, and $\mathrm{ABCG} 2$, in blood samples from healthy controls and CRC

Table 3 - Expression levels of ATP-binding cassette (ABC) transporters in different clinical stages of colorectal cancer.

\begin{tabular}{lccccc}
\hline $\begin{array}{l}\text { ABC } \\
\text { transporters }\end{array}$ & $\begin{array}{c}\text { Stage I } \\
(\mathbf{n}=7)\end{array}$ & $\begin{array}{c}\text { Stage II } \\
(\mathbf{n}=7)\end{array}$ & $\begin{array}{c}\text { Stage III } \\
(\mathbf{n}=17)\end{array}$ & $\begin{array}{c}\text { Stage IV } \\
(\mathbf{n}=31)\end{array}$ & $P$-value \\
\hline ABCB1 & $30.64 \pm 1.47$ & $25.61 \pm 4.38$ & $29.26 \pm 2.17$ & $29.67 \pm 0.57$ & 0.46 \\
ABCC1 & $27.23 \pm 0.49$ & $27.89 \pm 1.13$ & $27.88 \pm 0.82$ & $27.03 \pm 0.23$ & 0.59 \\
ABCG2 & $34.32 \pm 1.08$ & $33.46 \pm 0.74$ & $31.99 \pm 2.06$ & $32.13 \pm 1.19$ & 0.83 \\
\hline
\end{tabular}

Table 4 - Expression levels of ATP-binding cassette (ABC) transporters regarding gender and age in colorectal cancer patients.

\begin{tabular}{|c|c|c|c|c|c|c|}
\hline \multirow[b]{2}{*}{$\begin{array}{l}\mathrm{ABC} \\
\text { transporter }\end{array}$} & \multicolumn{2}{|c|}{ Gender } & \multicolumn{4}{|c|}{ Age (years) } \\
\hline & $\begin{array}{c}\text { Male } \\
(n=47)\end{array}$ & $\begin{array}{l}\text { Female } \\
(n=15)\end{array}$ & $P$-value & $\begin{array}{c}\geq 56 \\
(\mathrm{n}=25)\end{array}$ & $\begin{array}{c}<56 \\
(\mathrm{n}=37)\end{array}$ & $P$-value \\
\hline $\mathrm{ABCB} 1$ & $29.53 \pm 0.86$ & $28.21 \pm 2.17$ & 0.50 & $27.26 \pm 1.81$ & $30.53 \pm 0.59$ & 0.05 \\
\hline $\mathrm{ABCC} 1$ & $27.58 \pm 0.37$ & $26.76 \pm 0.23$ & 0.22 & $26.81 \pm 0.16$ & $27.77 \pm 0.46$ & 0.09 \\
\hline ABCG2 & $31.18 \pm 0.90$ & $28.91 \pm 2.31$ & 0.27 & $31.66 \pm 0.73$ & $29.93 \pm 1.39$ & 0.34 \\
\hline
\end{tabular}

Table 5 - Expression level of ATP-binding cassette (ABC) transporters in different body mass index (BMI) categories in colorectal cancer patients.

\begin{tabular}{|c|c|c|c|c|c|}
\hline \multirow[b]{2}{*}{$\begin{array}{l}\mathrm{ABC} \\
\text { transporters }\end{array}$} & \multicolumn{4}{|c|}{ BMI $\left(\mathrm{kg} / \mathrm{m}^{2}\right)$} & \multirow[b]{2}{*}{$P$-value } \\
\hline & $\begin{array}{l}<18.5 \\
(\mathrm{n}=5)\end{array}$ & $\begin{array}{c}18.5-24.9 \\
(\mathrm{n}=20)\end{array}$ & $\begin{array}{c}25-29.9 \\
(\mathrm{n}=15)\end{array}$ & $\begin{array}{c}\geq 30 \\
(\mathrm{n}=22)\end{array}$ & \\
\hline $\mathrm{ABCB} 1$ & $32.11 \pm 2.36$ & $28.30 \pm 1.60$ & $29.33 \pm 1.09$ & $29.29 \pm 1.62$ & 0.72 \\
\hline ABCC1 & $26.93 \pm 0.45$ & $27.94 \pm 0.71$ & $26.85 \pm 0.36$ & $27.35 \pm 0.40$ & 0.53 \\
\hline ABCG2 & $30.72 \pm 2.57$ & $30.55 \pm 1.79$ & $31.01 \pm 1.22$ & $30.43 \pm 1.66$ & 0.99 \\
\hline
\end{tabular}


subjects in Jeddah, Western Region of Saudi Arabia, and to reveal the relationship between the expression of those transporters and different aspects of colon cancer carcinogenesis. The results of the study showed that the 3 ABC transporters have higher mRNA expressions compared to controls, which can be used as a future diagnostic marker in CRC clinical diagnostic panel. However, the $3 \mathrm{ABC}$ transporters failed to show a significant contribution with tumor progression, age, gender, and BMI.

There are at least 15 members of the $\mathrm{ABC}$ transporter superfamily that promote the evasion of chemotherapeutic drugs and hinder MDR in cancer cells. ${ }^{27-29}$ Multidrug resistance has come to represent a significant obstacle concerning medicinal chemotherapy in the context of many human cancers. $\mathrm{ABCB} 1$ is the most significant human $\mathrm{ABC}$ transporter that has been widely studied for its implication in MDR via increasing cross-resistance to multiple anticancer drugs and therefore, leading to the defeat of chemotherapy in many malignancies. ${ }^{28-33}$ Nevertheless, there is another remarkable role in MDR of other $\mathrm{ABC}$ transporters, such as ABCC1 and ABCG2.34-36 The majority of studies that correlate cancer diagnosis and prognosis with the expression of $\mathrm{ABC}$ transporters were carried out on cancer tissues rather than in blood or other body fluid samples. A recent study performed on the Polish population to reveal the contribution of SNP 3435 and the expression of the $A B C B 1$ gene in lung cancer patients to clinicopathological parameters and treatment found that homozygous genotype (TT) and allele $\mathrm{T}$ are distributed widely in lung cancer patients compared to healthy subjects. Moreover, they found no difference in $A B C B 1$ expression level in lung cancer tissue and blood sample that was taken from patients before surgical treatment. However, the $A B C B 1$ mRNA level grew over time in blood samples taken from lung cancer patients, suggesting an important contribution of $\mathrm{ABCB} 1$ in lung cancer MDR. ${ }^{37}$ In the $A B C C 1$ and $A B C G 2$ genes, the alteration in the expression and the effectiveness of the corresponding gene and its product were located in the single nucleotide polymorphisms (SNPs). Thus, they might elevate the risk and impact the response of the cancer cells to the treatment and increase the capability of other types of cancer. ${ }^{38,39}$ In contrast to $A B C B 1$ and $A B C C 1$, the $A B C G 2$ gene genetic variations have been studied in various diseases; however, less was carried out on cancer. The role of $A B C G 2$ in drug resistance was more obvious in most of these studies than their capability to elevate the risk of the cancer. In 2018, a study was performed on bone marrow mononuclear cells from 96 acute myeloid leukemia (AML) patients showed that $A B C B 1, A B C C 1$,
$A B C C 4$, and $A B C G 2$ were highly expressed in AML patients, whereas $A B C B 4$ had a lower expression level. The 4 genes were significantly expressed at higher levels in poor drug response patients, which indicates a poor prognosis in AML. ${ }^{40}$ A study clarified that the adversity of smearing the ABCG2 protein was greater in the neoplasms of CRC patients with positive lymph nodes than in negative lymph nodes disease $30 \%$ and $6.7 \%$; $p<0.025)$. Therefore, it is possible that the expression of $A B C G 2$ could play a huge role in CRC progression and metastasis. ${ }^{41}$

In conclusion, this report recorded the expression of ABC transporters in blood samples of CRC patients in Saudi Arabia. The study exposed the diverse expression of $A B C$ transporters in CRC patients and discovered that $\mathrm{ABC}$ transporters were highly expressed in the blood of CRC patients. The findings also indicated that the expression of these $\mathrm{ABC}$ transporters could serve as a potential biomarker for the diagnosis of CRC. However, none of these transporters' expressions were related to clinical progression, age, gender, or BMI. In contrast, this study faced some limitations due to the small sample size; this limited the strength of the statistical analysis in some comparisons. Therefore, to emphasize these findings, more studies should be conducted with a larger number of patients with CRC tissue samples in the future.

Acknowledgment. The authors gratefully acknowledge Scribendi (www.scribendi. com) for English language editing.

\section{References}

1. Bray F, Ferlay J, Soerjomataram I, Siegel RL, Torre LA, Jemal A. Global cancer statistics 2018: GLOBOCAN estimates of incidence and mortality worldwide for 36 cancers in 185 countries. CA Cancer J Clin 2018; 68: 394-424.

2. Alsanea N, Abduljabbar AS, Alhomoud S, Ashari LH, Hibbert D, Bazarbashi S. Colorectal cancer in Saudi Arabia: incidence, survival, demographics and implications for national policies. Ann Saudi Med 2015; 35: 196-202.

3. Boyle P, Langman JS. ABC of colorectal cancer: epidemiology. BMJ 2000; 321: 805-808.

4. Jasperson KW, Tuohy TM, Neklason DW, Burt RW. Hereditary and familial colon cancer. Gastroenterology 2010; 138: 2044-2058.

5. Vasen HF, Tomlinson I, Castells A. Clinical management of hereditary colorectal cancer syndromes. Nat Rev Gastroenterol Hepatol 2015; 12: 88-97.

6. Hanahan D, Weinberg RA. The hallmarks of cancer. Cell 2000; 100: $57-70$.

7. Hanahan D, Weinberg RA. Hallmarks of cancer: the next generation. Cell 2011; 144: 646-674.

8. Krishna R, Mayer LD. Multidrug resistance (MDR) in cancer. Mechanisms, reversal using modulators of MDR and the role of MDR modulators in influencing the pharmacokinetics of anticancer drugs. Eur J Pharm Sci 2000; 11: 265-283. 
9. Longley DB, Allen WL, Johnston PG. Drug resistance, predictive markers and pharmacogenomics in colorectal cancer. Biochim Biophys Acta 2006; 1766: 184-196.

10. Imbrici P, Liantonio A, Camerino GM, De Bellis M, Camerino C, Mele A, et al. Therapeutic approaches to genetic ion channelopathies and perspectives in drug discovery. Front Pharmacol 2016; 7: 121.

11. Hediger MA, Clémençon B, Burrier RE, Bruford EA. The $\mathrm{ABCs}$ of membrane transporters in health and disease (SLC series): introduction. Mol Aspects Med 2013; 34: 95-107.

12. Dean M, Rzhetsky A, Allikmets R. The human ATP-binding cassette (ABC) transporter superfamily. Genome Res 2001; 11: 1156-1166.

13. Vasiliou V, Vasiliou K, Nebert DW. Human ATP-binding cassette (ABC) transporter family. Hum Genomics 2009; 3: 281-290.

14. Sarkadi B, Homolya L, Szakács G, Várdi A. Human multidrug resistance $\mathrm{ABCB}$ and $\mathrm{ABCG}$ transporters: participation in a chemoimmunity defense system. Physiol Rev 2006; 86: 1179-1236.

15. Toyoda Y, Hagiya Y, Adachi T, Hoshijima K, Kuo MT, Ishikawa T. MRP class of human ATP binding cassette (ABC) transporters: historical background and new research directions. Xenobiotica 2008; 38: 833-862.

16. Salonga D, Danenberg KD, Johnson M, Metzger R, Groshen S, Tsao-Wei DD, et al. Colorectal tumors responding to 5-fluorouracil have low gene expression levels of dihydropyrimidine dehydrogenase, thymidylate synthase, and thymidine phosphorylase. Clin Cancer Res 2000; 6: 1322-1327.

17. Showalter SL, Showalter TN, Witkiewicz A, Havens R, Kennedy EP, Hucl T, et al. Evaluating the drug-target relationship between thymidylate synthase expression and tumor response to 5-fluorouracil. Is it time to move forward? Cancer Biol Ther 2008; 7: 986-994.

18. Yaffee P, Osipov A, Tan C, Tuli R, Hendifar A. Review of systemic therapies for locally advanced and metastatic rectal cancer. J Gastrointest Oncol 2015; 6: 185-200.

19. Douillard JY, Cunningham D, Roth AD, Navarro M, James $\mathrm{RD}$, Karasek P, et al. Irinotecan combined with fluorouracil compared with fluorouracil alone as first-line treatment for metastatic colorectal cancer: a multicentre randomised trial. Lancet 2000; 355: 1041-1047.

20. Wang X, Zhang H, Chen X. Drug resistance and combating drug resistance in cancer. Cancer Drug Resist 2019; 2: 141-160.

21. National Cancer Registry (NCR) annual report, King Faisal Specialist Hospital and Research Centre (KFSHRC), 2015, Riyadh, Kingdom of Saudi Arabia. [Updated 2015. Cited 2019]. Available from URL: https://www.kfshrc.edu.sa/store/ media/810.pdf

22. Cole SP, Bhardwaj G, Gerlach JH, Mackie JE, Grant CE, Almquist KC, et al. Overexpression of a transporter gene in a multidrug-resistant human lung cancer cell line. Science 1992; 258: 1650-1654.

23. Doyle L, Ross DD. Multidrug resistance mediated by the breast cancer resistance protein BCRP (ABCG2). Oncogene 2003; 22: 7340-7358.

24. Johnsson A, Vallon-Christensson J, Strand C, Litman T, Eriksen J. Gene expression profiling in chemoresistant variants of three cell lines of different origin. Anticancer Res 2005; 25: 26612668.

25. Choudhuri S, Klaassen CD. Structure, function, expression, genomic organization, and single nucleotide polymorphisms of human ABCB1 (MDR1), ABCC (MRP), and ABCG2 (BCRP) efflux transporters. Int J Toxicol 2006; 25: 231-259.
26. Szakács G, Annereau JP, Lababidi S, Shankavaram U, Arciello A, Bussey KJ, et al. Predicting drug sensitivity and resistance: Profiling $\mathrm{ABC}$ transporter genes in cancer cells. Cancer Cell 2004; 6: 129-137.

27. Szakács G, Paterson JK, Ludwig JA, Booth-Genthe C, Gottesman MM. Targeting multidrug resistance in cancer. Nat Rev Drug Discov 2006; 5: 219-234.

28. Fletcher JI, Williams RT, Henderson MJ, Norris MD, Haber M. ABC transporters as mediators of drug resistance and contributors to cancer cell biology. Drug Resist Updat 2016; 26: 1-9.

29. Li W, Zhang H, Assaraf YG, Zhao K, Xu X, Xie J, et al. Overcoming $\mathrm{ABC}$ transporter-mediated multidrug resistance: molecular mechanisms and novel therapeutic drug strategies. Drug Resist Updat 2016; 27: 14-29.

30. Ambudkar SV, Dey S, Hrycyna CA, Ramachandra M, Pastan I, Gottesman MM. Biochemical, cellular, and pharmacological aspects of the multidrug transporter. Annu Rev Pharmacol Toxicol 1999; 39: 361-398.

31. Sharom FJ. The P-glycoprotein multidrug transporter. Essays Biochem 2011; 50: 161-178.

32. Holohan C, Van Schaeybroeck S, Longley DB, Johnston PG. Cancer drug resistance: an evolving paradigm. Nat Rev Cancer 2013; 13: 714-726.

33. Silva R, Vilas-Boas V, Carmo H, Dinis-Oliveira RJ, Carvalho F, de Lourdes Bastos M, et al. Modulation of P-glycoprotein efflux pump: induction and activation as a therapeutic strategy. Pharmacol Ther 2015; 149: 1-123.

34. Zhang YK, Wang YJ, Gupta P, Chen ZS. Multidrug resistance proteins (MRPs) and cancer therapy. AAPS J 2015; 17: 802-812.

35. Natarajan K, Xie Y, Baer MR, Ross DD. Role of breast cancer resistance protein (BCRP/ABCG2) in cancer drug resistance. Biochem Pharmacol 2012; 83: 1084-1103.

36. Mao Q, Unadkat JD. Role of the breast cancer resistance protein (BCRP/ABCG2) in drug transport-an update. AAPS J 2015; 17: 65-82.

37. Zawadzka I, Jeleń A, Pietrzak J, Żebrowska-Nawrocka M, Michalska K, Szmajda-Krygier D, et al. The impact of ABCB1 gene polymorphism and its expression on non-small-cell lung cancer development, progression and therapy- preliminary report. Sci Rep 2020; 10: 6188.

38. Abdulkhaleq MM, Al-Ghafari AB, Yezerski A, Al Doghaither HA, Abusanad AM, Omar UM. Novel association between heterozygous genotype of single nucleotide polymorphism $\mathrm{C} 218 \mathrm{~T}$ in drug transporter $\mathrm{ABCC} 1$ gene and increased risk of colon cancer. Saudi Med J 2019; 40: 224-229.

39. Campa D, Müller P, Edler L, Knoefel L, Barale R, Heussel C, et al. A comprehensive study of polymorphisms in ABCB1, ABCC2 and ABCG2 and lung cancer chemotherapy response and prognosis. Int J Cancer 2012; 131: 2920-2928.

40. Liu B, Li L-J, Gong X, Zhang W, Zhang H, Zhao L. Coexpression of ATP binding cassette transporters is associated with poor prognosis in acute myeloid leukemia. Oncol Lett 2018; 15: 6671-6677.

41. Liu HG, Pan YF, You J, Wang OC, Huang KT, Zhang XH. Expression of ABCG2 and its significance in colorectal cancer. Asian Pac J Cancer Prev 2010; 11: 845-848. 